\title{
A Novel Urea Amperometric Biosensor Based on Secretion of Wild Winter Jasmine Petal Cells Modified on Graphite-Epoxy Composite Electrode
}

\author{
Yongchun Zhu, Chunyan Pang, Hongyan Gao, Yue Dong and Jie Lu \\ College of Chemistry and Life Science, Shenyang Normal University, Shenyang 110034, Liaoning, China
}

Received: April 07, 2013 / Accepted: April 08, 2013 / Published: June 25, 2013.

\begin{abstract}
A new kind of amperometric biosensor was designed for detection of urea with a high selectivity, sensitivity and wide detection range based on the secretion of whole living cells of wild winter jasmine petals paste covered on a graphite-epoxy composite basic electrode surface. The petal paste from mashed fresh winter jasmine petals was tightly fixed on the basic electrode surface with teflon thin film to keep it contact with electrode surface. During the mashing process, the winter Jasmine petal cells secrete some species, which are electrochemical active and gives an oxidation peak at $0.316 \mathrm{~V}$ (vs. SCE) in differential pulse voltammetric curve. The interactions of secreted species with urea molecules, and results in the decrease the oxidation peak current. The oxidation peak current was decreased linearly with the logarithm of urea concentration in the range of $1.3 \times 10^{-16} \sim 4.57 \times 10^{-8} \mathrm{M}$ with the detection limit of $1.3 \times 10^{-16} \mathrm{M}$.
\end{abstract}

Key words: Amperometric biosensor, secretion of plant cells, urea, wild winter Jasmine petal cells, fluorescent spectrometry.

\section{Introduction}

Whole living cells have been used as the bio-recognition units in fabrications of biosensors [1-3] and biochips [4, 5] for a long time, and had been considered to have some unique advantages over the common enzymes, DNA and proteins, but one of major problems is its selectivity due to there are many enzymes and other recognition units existed in a single cell, and respond to many physical, chemical and biological stimuli from its environment. So, one of the main projects for the whole living cell biosensor development is to find out a kind of cells only responds to one target. In our previous study, carnation petal cells paste can be used as bio-recognition unit in amperometric biosensor, and sensitively selectively responds to urea molecule due to its unique molecular fertilizer of plants absorbed

\footnotetext{
Corresponding author: Yongchun Zhu, professor, research field: electroanalytical chemistry. E-mail: yongchunzhu@126.com.
}

through leaves and other parts of plants [6-9].

In the present paper, the naturally growing winter Jasmine petals were chosen as bio-recognition unit to build up an amperometric biosensor for the detection of urea. Some interesting results were obtained, and reported here.

\section{Experiments}

\subsection{Instrument and Reagents}

Electrochemical experiments were preformed on an Electrochemical Analyzer (model CHI620B, Chen Hua Instrument Company, Shanghai) with three electrodes system, a mashed petals of winter jasmine modified graphite-epoxy composite electrode as the working electrode, a piece of platinum wire as the counter electrode and saturated calomel electrode as the reference electrode, all potential were measured respect to this reference electrode.

Fluorescence experiments were carried out on a fluorescent spectroscopy. 
Potassium chloride, urea, disodium hydrogen phosphate, potassium dihydrogen phosphate, ammonium chloride and Potassium nitrate were all analytical pure, and prepared as electrolyte solution, standard stock solution and $\mathrm{pH}$ buffer solution. All solutions were prepared with ultrapure water (18.3 M $\Omega$ from mili-Q water system). All electrolyte solution was deaerated with high purity nitrogen gas to remove oxygen prior to use.

\subsection{Fabrication of Biosensor}

The graphite-epoxy composite electrode (GECE) [10] was chosen as the basic electrode due to its higher affinity to organic and bio-molecules and tissues, which was the prepared with the mixture of $2.00 \mathrm{~g}$ of graphite powder, $0.60 \mathrm{~g}$ of epoxy resin and $0.50 \mathrm{~g}$ of polyamide resins, filled into a pieces of glass tube (the inner diameter was about $4 \mathrm{~mm}$ ) with a piece of copper wire as the electrode lead. The prepared GECE was dried in air for one week, and polished the up end with thin sandpaper and glassy paper into mirror-like surface [11].

The winter Jasmine flower used in this work was the common one as flowers in campus of Shenyang Normal University in china. A piece petal was picked off from a fresh winter jasmine flower, mashed into paste with the basis electrode on a clean glass plane. The petal paste was coated on the basic electrode surface, and covered tightly with polytetrafluoroethylene (PTFE) membrane [10] in order to obtain a quickly responds of the biosensor to the urea in aqueous solution.

\subsection{The Measurement Procedure}

\subsubsection{Electrochemical Experimental Procedure}

Three electrodes were put into a $0.1 \mathrm{M} \mathrm{KCl}$ electrolyte solution ( $\mathrm{pH}$ 7.5), performed the cyclic voltammetry and differential pulse voltammetry experiments as the basic curves of the biosensor, and then added urea solution with different concentration from lower to concentrated into the electrolyte solution, and performed the electrochemical experiments again, the curves with the interaction of urea in different concentrations were obtained.

2.3.2 Fluorecent Spectrophotometry Experiment Procedure

A piece of petal was picked off from fresh winter Jasmine flower or its paste were covered on a reflection mirror (a part of the fluorescent spectroscopy for solid materials from the instrument co.) with a piece of PTFE, and put in the chamber of the fluorescent spectroscopy, performed the experiments, and recorder the fluorescent spectra for winter Jasmine petal and carnation petal paste.

The reflection mirror with winter jasmine petal paste was put into a fluorescent cell with different concentrations for a given time, and then performed the fluorescence experiments. The recorded fluorescent spectra were used to test the interaction of winter jasmine paste with urea molecules.

\section{Results and Discussion}

\subsection{Designation and Characterization of the Biosensor}

\subsubsection{Designation Consideration of the Biosensor}

According to the excitability property of plants [6-7], the cells tissues and organs in plants alter their internal conditions and external reactions under the influence of various environmental factors, referred to as irritants such as temperature, chemicals, mechanical wounding, insects, cutting to release some chemicals as secretion and fast transfer these signals to whole plant as well as the plants nearby. In this way, the high plants can respond to small amount of chemicals sensitively and selectively. There are at least two steps in this sensing process. The irritant chemicals are firstly recognized by the bio-recognition molecules with the help of enzymatic systems $[12,13]$ in the cells of the plant tissue contacted with the chemicals and release the secretion to responds to the chemical irritant. Secondly, the cells transfer this signal to the nearby cells through the plasmodesmata [14], and made the nearby cells secret the same secretion. This signal was amplified largely according to the quorum 
sensing theory [15]. In biosensor design, we pay more attention to the first step using variety of enzymes, DNA, to recognize the target molecules, and build up several kinds of biosensors. But we have not find a suitable way to utilize the bio-amplification function of cells in the biosensor deign [16].

The plant tissues have been used in tissue biosensors [17], but the communication process between cells do not monitored by transducers without improvement in the sensitivity of the biosensor. If the plant tissue was mashed into paste, the cells are broken off from the tissue, and then they self reorganize onto the basic electrode surface $[18,19]$ into a pattern similar to that in the petal tissue. The self-reorganized cells can keep the quorum sensing number [15] and transfer the biological signal to electrode. In order to keep the petal paste and cells do not go out into solution from the electrode surface during the experiments, a piece of highly sensitive PTFE membrane was used to cover the paste tightly on the electrode surface. According to this idea, the biosensor was fabricated as described in section 2.2, and characterized as the followings.

3.1.2 Electrochemical Characterization of the Biosensor

The three electrodes were set up in electrolyte solution $(0.1 \mathrm{M} \mathrm{KCl}$ and $\mathrm{pH}=7.5$ Phosphate buffer $)$ with or without urea. Cyclic voltammetric (CV) and differential pulse voltammetric (DPV) experiments were performed; the CV and DPV curves were obtained as shown in Fig.1. The biosensor shows an irreversible oxidation peak at $0.37 \mathrm{~V}$, and an irreversible reduction peak at $0.26 \mathrm{~V}$ (Fig. 1a, curve 1). The two redox peaks may belong to the some redox active substances. With the addition of urea molecule about $1.0 \times 10^{-5} \mathrm{M}$ urea in the solution, the redox potentials were not shifted, but the redox currents were reduced (curve 2 in Fig. 1a). This result which indicates the urea molecules can react with the redox active substance, form a redox inactive ones, and result in the decrease of the redox current.

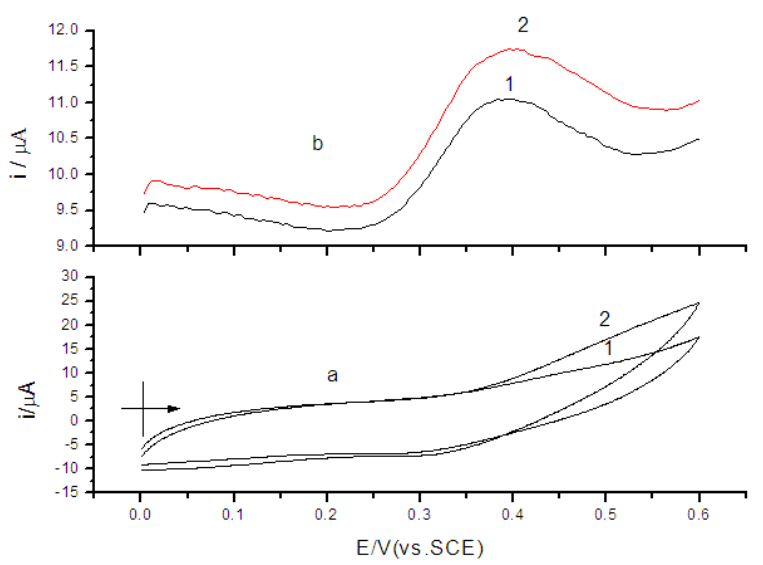

Fig. 1 (a) The CV curves and (b) DPV curves of the biosensor with urea (1) without urea; (2) in $0.1 \mathrm{M} \mathrm{KCl}$ electrolyte at $\mathrm{pH}=7.5$. Quiet time: $2 \mathrm{~s}$ scan rate: $0.05 \mathrm{v} / \mathrm{s}$, urea concentration of $1.0 \times 10^{-5} \mathrm{M}$.

The oxidation DPV curves with one oxidation peak at $0.316 \mathrm{~V}$ are sensitively indicated the same results as shown in Fig. 1b. So the decrease of the peak current at $0.316 \mathrm{~V}$ can be used to monitor the concentration of urea in solution.

Under the same conditions, the CV experiments were performed at different scan rate. The oxidation peak current at $0.37 \mathrm{~V}$ was increased linearly with the increase of scan rate. The regression equation was as the following.

$$
\begin{aligned}
& i_{p a}=-0.4603+0.08929 v, \\
& R=0.9958, S D=0.4828
\end{aligned}
$$

This relationship indicates that the redox process is a surface controlled process. This result is the evident for the design of the biosensor, in which the cells are located at the electrode surface. The electrode can directly be used in monitoring the electrochemical active species during the biological process.

According to the plant secretion theory [20,21], the higher plant can release some signaling substances to responds to the irritation from the environment such as mechanical or chemicals. If the released substances are electrochemically active, then the related process can be monitored by electrochemical methods [22, 23]. Petals of flowers contain some polyhydroxyl phenols such as catechols [24], which may give the oxidation peak at about $0.3 \mathrm{~V}$. Polyhydroxyl phenols can also 
react with urea to form electrochemical inactive substances [25].

3.1.3 Fluorecent Spectrophotometric Characterization of the Biosensor

In order to find the evidence for the about process, the fluorescence spectrophotometry was used to test the system. The fluorescence spectra from winter Jasmine petal, winter Jasmine petal paste and after interaction with urea were recoded as shown in Fig. 2.

In Fig. 2, it can be seen, winter jasmine petal shows ten obvious fluorescent peaks located at 382.00, 416.06, 446.96, 460.00, 482.98, 526.02, 540.00, 572.94, 605.00, 715.07 (Fig. 2a), but after the carnation panel was mashed into a paste, the paste shows 14 fluorescent peaks. There are four new peaks located at 362.00, 521.02, 595.94 and $761.94 \mathrm{~nm}$ appear as shown in Fig. 2b. These fluorescent peaks were decreased in their intensities, or even disappeared in the contacting with urea solution (1.0 $\left.\times 10^{-4} \mathrm{M}\right)$ (Fig. 2c), The results indicate that mashing process makes the winter jasmine petal secrete some electrochemical active substances, which interact with urea molecules and lose their electrochemical activity and fluorescent properties.

\subsection{The Effect of Urea Concentration and Working} Curve

Under the optimal conditions, the DPV experiments were performed at different urea concentrations in the range of $4.57 \times 10^{-8} \sim 1.3 \times 10^{-17} \mathrm{M}$, and the DPV curves were recorded as shown in Fig. 3a. The anodic peak current was plotted against the logarithm of urea concentration as a straight line as shown in the inserted plot in Fig. 3b with a regression equation of:

$$
\begin{aligned}
& i_{p a}=3.995-0.6278 \log (c / \mathrm{M}) \\
& R=0.998, S D=0.183
\end{aligned}
$$

This relation indicates the responds of the biosensor to the urea concentration follows a first order reaction similar to that of carnation petal cell paste modified biosensor [7]. This straight line can be served as the standard working curve for the detection of urea in the

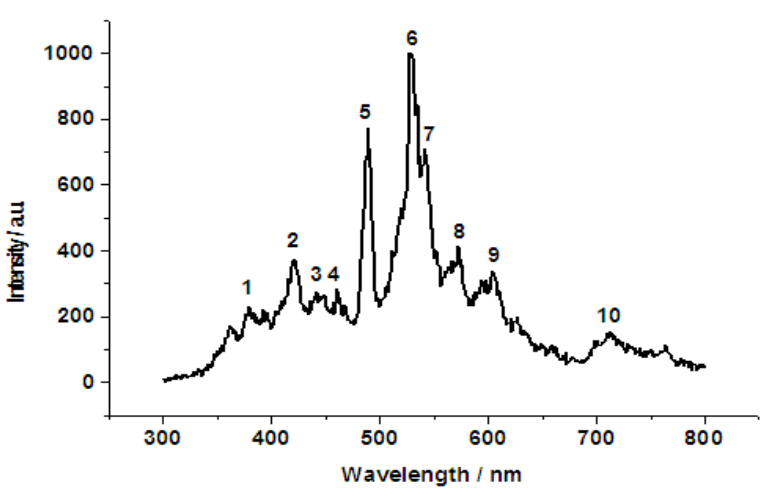

(a)

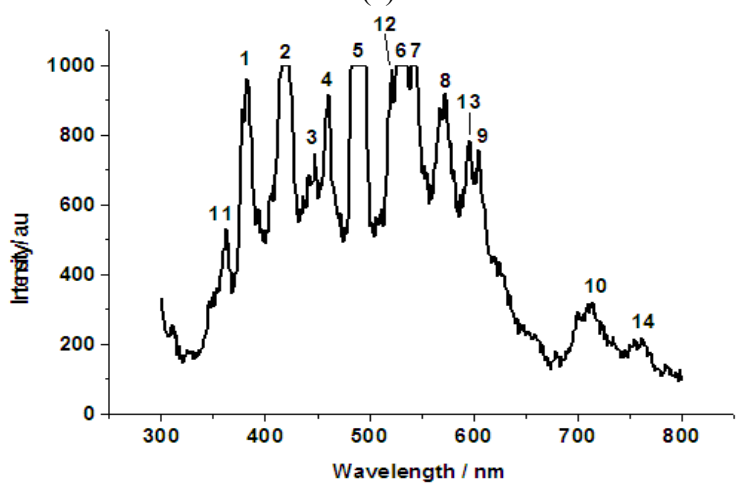

(b)

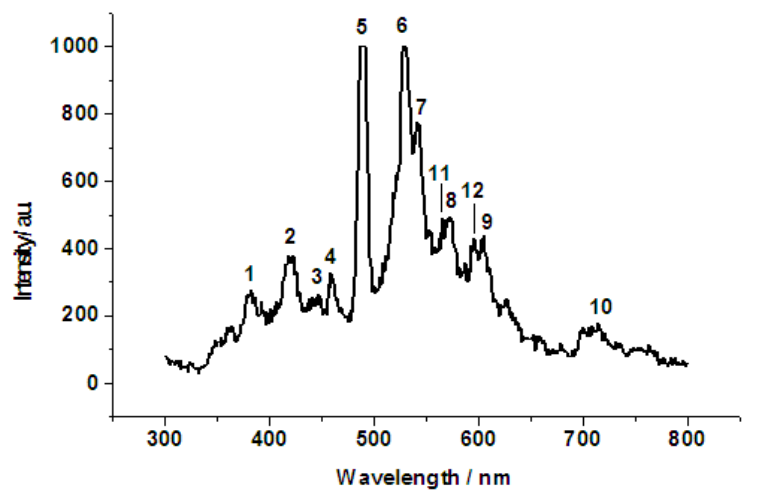

(c)

Fig. 2 The fluorescent spectra of winter jasmine petal (a) mashed paste of winter jasmine petals without (b) and with urea (c) $\lambda / \mathrm{nm}: 1,382.00 ; 2,416.06 ; 3,446.96 ; 4,460.00$; $5,482.98 ; 6,526.02 ; 7,540.00 ; 8,572.94 ; 9,605.00 ; 10,715.07$; $11,362.00 ; 12,521.02 ; 13,595.94 ; 14,761.94$.

concentration range of $6.98 \times 10^{-6} \sim 1.3 \times 10^{-17} \mathrm{M}$ with a detection limit of $1.3 \times 10^{-16} \mathrm{M}$.

\section{Conclusions}

In this paper, Amperometric biosensor was designed and fabricated based on secretion of whole living cells of carnation petals for detection of urea. Some conclusions were as the followings. 

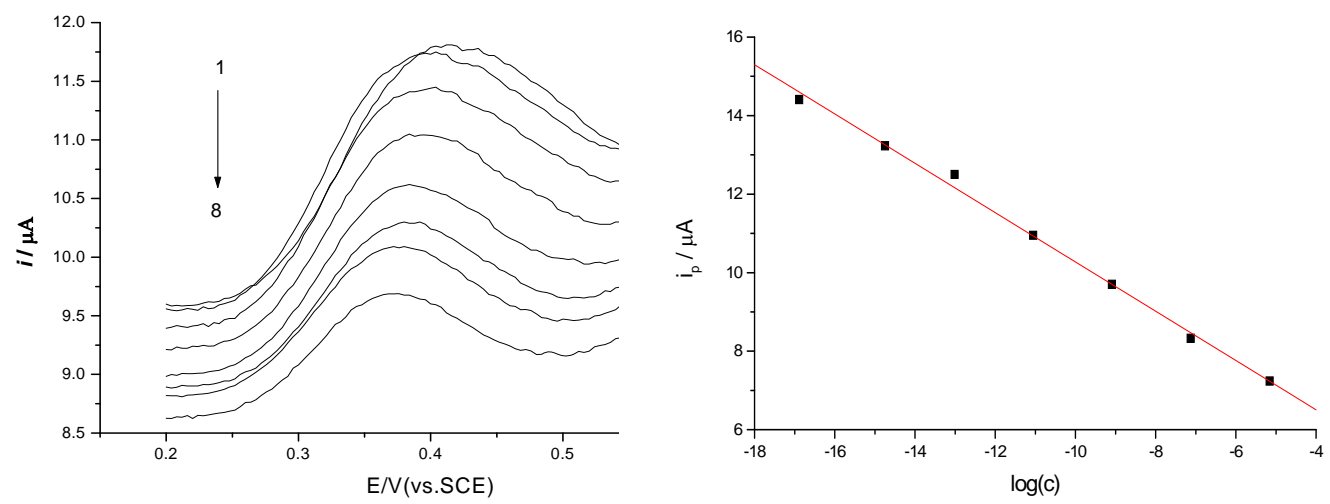

Fig. 3 The DPV curves of biosensor at different concentration of urea, and the insert shows the relationship between anodic peak current and logarithm of concentration of urea. Concentration (M): (1) 0.00 ; (2) $1.30 \times 10^{-17}$; (3) $1.79 \times 10^{-15}$; (4) $9.68 \times$ $10^{-14}$; (5) $8.82 \times 10^{-12}$; (6) $8.12 \times 10^{-10}$; (7) $7.5 \times 10^{-8}$ and (8) $6.98 \times 10^{-6}$. The other experimental conditions were the same as those in Fig. 1.

The whole cells of carnation petal paste modified graphite-epoxy composite electrode can be served as biosensor for the detection of urea with very high sensitivity and selectivity. The optimal experimental conditions were obtained as $\mathrm{PH} 7.5$, contact time of $150 \mathrm{~s}$, quiet time of $2 \mathrm{~s}$. The biosensor responds to urea in the concentration ranges of $1.3 \times 10^{-16} \sim 4.57 \times$ $10^{-8} \mathrm{M}$ with the deviation limit of $1.3 \times 10^{-16} \mathrm{M}$.

\section{Acknowledgments}

The author would like to acknowledge the financial supports of the Chinese National Science Foundation (20875063), Liaoning Education Minister (2004-c022) and National Key Laboratory on Electroanalytical Chemistry (2006-06), Shenyang Sciences and Technology Bureau Foundation (2007-GX-32).

\section{References}

[1] J.W. Parce, J.C. Owicki, K.M. Kercso, G.B. Sigal, V.C.W. Muir, L.J. Bousse, et al., Detection of cell-affecting agents with a silicon biosensor, Science 246 (4927) (1989) 243-247.

[2] T. Elad, J.H. Lee, S. Belkin, M.B. Gu, Microbial whole-cell arrays, Biotechnol 1 (2) (2008) 137-148.

[3] S. Daunert, G. Barrett, J.S. Feliciano, R.S. Shetty, S. Shrestha, W. Smith, Spencer genetically engineered whole-cell sensing systems: Coupling biological recognition with reporter genes, Chem. Rev 100 (7) (2000) 2705-2738 .

[4] E. Jamiln, P.K. Sorger, K.F. Jensen, Review article cells on chips, Nature 442 (2006) 403-411.

[5] J.M.H. King, P.M. DiGrazia, B. Applegate, R. Burlage, J. Sanseverino, P. Dunbar, et al., Rapid, sensitive bioluminescent reporter technology for naphthalene exposure and biodegradation, Science 249 (1990) 778-781.

[6] A.M. Aravanis, B.D. DeBusschere, A.J. Chruscinski, K.H. Gilchrist, B.K. Kobilka, G.T.A. Kovacs, A genetically engineered cell-based biosensor for functional classification of agents, Biosensors and Bioelectronics 16 (7-8) (2001) 571-577.

[7] C. Pang, Y. Zhu, H. Gao, Y. Dong, J. Lu, A novel urea amperometric biosensor based on secretion of carnation petal cells modified on graphite-epoxy composite electrode, Analyst 136 (4) (2011) 841-846.

[8] S. Uchiyama, G.A. Rechnitz, Biosensors using flowers as catalytic material, Analytical Letters 20 (3) (1978) 451-470.

[9] J.Q. Wang, J.C. Chou, T.P. Sun, pH-based potentiometrical flow injection biosensor for urea, Sensors and Actuators 91 (1-3) ( 2003) 5-10.

[10] N.S. Lawrence, M. Thompson, D. James, L. Jiang, G.J.J. Timothy, G.R. Compton, Carbon-epoxy electrodes: Unambiguous identification of authentic triple-phase (insulator/solution/electrode) processes, Chemical Communications 2012 (10) (2002) 1028-2029.

[11] M.K. SezgIntürk, T. Goktug, E. Dinckaya, Detection of benzoic acid by an amperometric inhibitor biosensor based on mushroom tissue homogenate, Food Technol Food Technol. Biotechnol 43 (4) (2005) 329-334.

[12] M. Awais, M. Sato, K. Sasaki, Y. Umezawa, A genetically encoded fluorescent indicator capable of discriminating estrogen agonists form antagonists in living cells, Anal. Chem. 76 (2004) 2181-2186. 

Cells Modified on Graphite-Epoxy Composite Electrode

[13] S.F. Arnold, M.K. Robinson, A.C. Notides, L.J. Guillette, J.A. Lachlan, A yeast estrogen screen for examining relative exposure of cells to natural and xenoestrogens. Environ, Health Persp. 104 (1996) 544-548.

[14] D. Gershon, Cell signalling: Making connections, Nature 432 (2004) 243-249.

[15] C.A.J. Joost, C.J. De Keersmaecker Sigrid, E. De Vos Dirk Vanderleyden Jos, Small molecules for interference with cell-cell-communication systems in gram-negative bacteria, Curr. Med. Chem. 15 (21) (2008) 2144-2156.

[16] H.Y.N. Holman, M.C. Martin, W.R. McKinney, Synchrotronbased FTIR spectromicroscopy: Ytotoxicity considerations, J. Biol. Phys. 29 (2-3) (2003) 275-286.

[17] T. Osakai, T. Kakutani, M. Senda, A novel amperometric urea sensor, Anal. Sci. 4 (5) (1988) 529-530.

[18] R.C. Engstrom, Electrochemical pretreatment of glassy carbon electrodes, Anal. Chem. 54 (13) (1982) 2310-2314.

[19] D. Nematollahi, M. Rafiee, L. Fotouhi, Mechanistic study of homogeneous reactions coupled with electrochemical oxidation of catechols, J. Iran. Chem. Soc. 6 (3) (2009) 448-476.

[20] V.R. Victoria, Autofluorescence of plant secreting cells as a biosensor and bioindicator reaction, Journal of Fluorescence 13 (5) (2003) 403-420.

[21] D.A. Stenger, W. Guenter, G. Edward, W. Keefer, K.M. Shaffer, J.D. Andreadis, et al., Detection of physiologically active compounds using cell-based biosensors, Trends in Biotechnology 19 (8) (2001) 304-309.

[22] E.D. Mcalister, J. Myers, Time course of photosynthesis and fluorescence, Science 92 (2385) (1940) 241-243 .

[23] J.J. Pancrazio, J.P. Whelan, D.A. Borkholder, W. Ma, D.A. Stenger, Development and application of cell-based biosensors, annals of biomedical engineering, Annals of Biomedical Engineering 27 (6) (1999) 697-711.

[24] B.M. Paddle, Biosensors for chemical and biological agents of defence interest, Biosens. Bioelectron 11 (11) (1996)1079-1113.

[25] M. Bourouina, A. Ourari, S. Bourouina-bacha, The effect of membrane permeability on the response of a catechol biosensor, Microchim Acta 163 (2008) 171-178. 